Jerneja Kavčič

UDK [811.124'02+811.14'02]:81'366.58

Filozofska fakulteta, Univerza v Ljubljani

DOI: $10.4312 /$ vestnik.11.29-47

Slovenija

jerneja.kavcic@ff.uni-lj.si

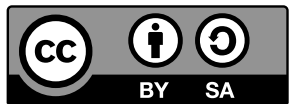

\title{
IZRAŽANJE ČASOVNIH RAZMERIJ V LATINSKIH IN GRŠKIH ACI IN NCI STAVKIH: NEKAJ NOVEJŠIH SPOZNANJ IN NJIHOVI UPORABNI VIDIKI
}

UVOD

Tema pričujočega prispevka so AcI (accusativus cum infinitivo) in $\mathrm{NcI}$ (nominativus cum infinitivo) stavki v latinščini in stari grščini. Obravnavam nekaj novejših spoznanj, ki se tičejo izražanja časovnih razmerij (Bentein 2018, Kavčič 2016, Kavčič 2019, Orešnik 1999: 77) in opozarjajo na (delne) skupne značilnosti med omenjeno konstrukcijo v klasičnih in modernih jezikih (t.j. v angleščini in nizozemščini). Navajam študije, ki se osredotočajo na poklasično grščino in arhaično latinščino, dodajam podatke za klasični obdobji obeh jezikov (5. st. pr. Kr. v primeru grščine in 1. st. pr. Kr. v primeru latinščine) in predlagam razlago, zakaj se je v grščini postopoma v vlogi izražanja preddobnosti uveljavil infinitiv perfekta. Ob koncu obravnavane pojave osvetlim z vidika njihovega pomena za didaktiko klasičnih jezikov.

\section{2}

TRADICIONALNI POGLED

Stavki, ki jih obravnavam v pričujočem članku, se v slovnicah klasičnih jezikov imenujejo tudi »deklarativni« ali »povedni« nedoločniški (pol)stavki. Ti stavki so - tako v latinščini kot v grščini - praviloma odvisni od glagolov govorjenja in mišljenja in po pomenu ustrezajo indikativu v finitnih stavkih. V tem smislu se razlikujejo od nedoločniških polstavkov, ki se nanašajo na potencialno zadobno dejanje; v stavku volo abire »hočem oditi« se denimo nedoločnik (abire) nanaša na dejanje, ki se bo morda zgodilo (v prihodnosti), takšni stavki pa se imenujejo tudi dinamični. Primer povednega nedoločniškega polstavka je spodnji (latinski) stavek, v katerem infinitiv prezenta glagola biti (esse) izraža dejstvo, da je nekaj povsem gotovo:

(1) Putant id esse certissimum (Cic., Verr. 2.1.141) Menijo, da je to povsem gotovo. 
Ker imajo obravnavani stavki v skladenjskem smislu obliko AcI ali NcI stavkov, kar pomeni, da je osebek odvisnega (t.j. nedoločniškega) polstavka izražen s tožilnikom ali pa je izpusten (in sonanašalen $\mathrm{z}$ osebkom nadrednega stavka), zanje v nadaljevanju uporabljam izraz AcI/NcI stavki.

Tako v latinščini kot v stari grččini se v AcI/NcI stavkih lahko izražajo dejanja, ki so glede na čas, izražen v nadrednem stavku, istodobna, preddobna ali zadobna. Pri tem se infinitiv prezenta ( $\mathrm{v}$ obeh jezikih) uporablja za izražanje istodobnosti, tako kot $\mathrm{v}$ zgornjem primeru (1): infinitiv prezenta esse izraža, da dejstvo, da je nekaj gotovo, velja $\mathrm{v}$ času, na katerega se nanaša tudi nadredni glagol (namreč putant »mislijo«). Infinitiv futura se nadalje v obeh jezikih uporablja v vlogi izražanja zadobnosti, medtem ko so bile nekoliko bolj zapletene razmere pri izražanju preddobnosti - tem je namenjen tudi večji del pričujočega članka.

Splošno sprejeto je, da se v latinščini v vlogi izražanja preddobnosti uporablja infinitiv perfekta; denimo v naslednjem stavku, kjer venisse, infinitiv perfekta glagola venio »pridem«, izraža dejanje, preddobno glede na čas nadrednega stavka:

(2) Ait venisse illum in somnis ad se mortuom (Plaut., Most. 490) Pravi, da je oni mrtev prišel $\mathrm{k}$ njemu $\mathrm{v}$ sanjah.

V stari grščini se po prevladujočem mnenju za izražanje preddobnosti uporablja infinitiv aorista. Ta prevzame vlogo, kakršno ima indikativ aorista $\mathrm{v}$ finitnih stavkih (prim. Rijksbaron 2006: 97). V naslednjem stavku tako infinitiv aorista glagola $\delta \rho \alpha ́ \omega ~ » s t o r i t i \ll$ $(\delta \rho \tilde{\alpha} \sigma \alpha \iota)$ izraža, da so bila dejanja, na katera se nanaša, preddobna glede na čas nadrednega stavka:

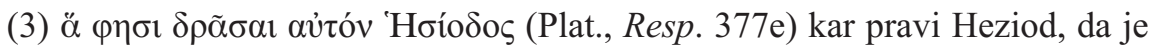
oni (bil) storil

Poleg infinitiva aorista je stara grščina poznala tudi infinitiv perfekta, ki mu večina slovnic namenja razmeroma malo pozornosti. Delni razlog je brez dvoma ta, da v klasični dobi perfekt, s tem pa tudi infinitiv perfekta, še ni izpričan pri vseh glagolih. Rijksbaron (2002: 98) tako zaključi, da je infinitiv perfekta v konstrukciji AcI/NcI redek in da izraža - kadar je v tej vlogi izpričan - stanja, istodobna $\mathrm{z}$ nadrednim stavkom.

Nekoliko drugačno je naziranje novejše študije (Bentein 2018: 88-89): v klasični dobi naj bi infinitiv perfekta prevladoval v vlogi izražanja preddobnosti v AcI/NcI stavkih, pri čemer je v isti vlogi izpričan tudi infinitiv aorista. Četudi trditev nasprotuje prej omenjenemu, prevladujočemu stališču, pa je skladna z danes vse bolj uveljavljenim

1 Pri tem velja, da se konstrukcija AcI uporablja za aktivnimi nadrednimi glagoli (govorjenja in mišljenja) v grščini in latinščini v primeru nesonanašalnih osebkov glavnega in odvisnega stavka, v latinščini pa tudi v primeru sonanašalnih osebkov; sicer se uporablja konstrukcija NcI. 
prepričanjem o vlogi perfekta v klasični grščini (5. st. pr. Kr.), po katerem naj bi se v tej dobi uveljavil perfekt, primerljiv s perfektom v modernih jezikih (na primer v angleščini in nizozemščini). Ta perfekt naj bi izražal preteklo dejanje, ki ostaja aktualno v sedanjosti, in naj bi nadomestil t.i. rezultativni perfekt (Haspelmath 1992: 92). Slednji poudarja stanje kot posledico preteklega dejanja, grščina pa ga je poznala v najstarejših obdobjih (prim. loc. cit.). Če se postavimo na stališče, da se je v grščini klasične dobe pojavil perfekt, primerljiv s perfektom v modernih jezikih, kot sta angleščina in nizozemščina, je obenem treba upoštevati, da v slednjih infinitiv perfekta izraža preddobnost v (povednih) nedoločniških stavkih. Comrie (1981: 55) ugotavlja, da ima v spodnjem primeru infinitiv perfekta to have been enako vlogo kot angleški čas simple past $\mathrm{v}$ finitnih stavkih; ta čas se namreč uporabi, če se isti nedoločniški polstavek parafrazira z osebno glagolsko obliko:

(4) The security officer believes Bill to have been in Berlin before the war. Uslužbenec varnostne službe verjame, da je bil Bill pred vojno v Berlinu.

To pomeni, da lahko v obravnavani konstrukciji (v angleščini) infinitiv perfekta prevzame vlogo tako angleškega časa present perfect kot vlogo angleškega časa simple past (loc. cit.). Enak pojav v nizozemščini opisujeta ter Beek (2011: 43) in Zwart (2014: 383). Slednji dodaja, da se infinitiv perfekta v omenjeni vlogi uporablja tako v dovršnem kot v nedovršnem pomenu (Zwart 2014: 383).

Posledično se izkaže za povsem mogoče tudi, da je v klasični grščini podobno vlogo opravljal, morda vzporedno z infinitivom aorista, infinitiv perfekta - četudi bi ta domneva, kot bo razloženo v nadaljevanju, zahtevala dodatno utemeljitev.

\section{3 NOVEJŠA SPOZNANJA O ČASOVNIH RAZMERJIH V ACI/NCI STAVKIH}

\subsection{Težnja po stanjskosti in izražanje istodobnosti}

Kot rečeno, se po tradicionalni razlagi infinitiv prezenta tako v latinščini kot v grščini uporablja za izražanje istodobnosti, pri čemer se domneva, da se v vlogi infinitiva prezenta, ki izraža istodobnost, lahko uporabi kateri koli glagol. S tega vidika je presenetljiva Thorleyeva ugotovitev, da se - vsaj v poklasični grščini - obravnavana konstrukcija uporablja tako rekoč izključno za izražanje istodobnih stanj (Thorley 1989: 295). Z drugimi besedami, uporabljali naj bi se zgolj stavki, kakršen je spodnji primer iz Nove Zaveze; v njem infinitiv prezenta glagola biti (Ẽ̃vaı) izraža stanje (namreč obstoj kraja

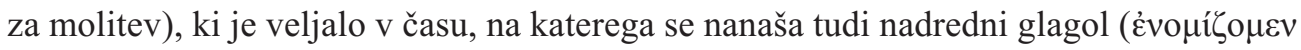
»mislili smo«): 


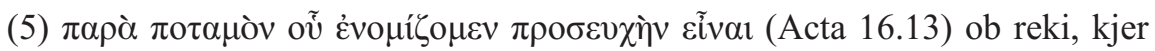
smo mislili, da je kraj za molitev

Podobne pojave so opazili tudi v modernih jezikih. Paul Postal je v monografiji On raising opozoril, da se $\mathrm{v}$ angleščini v AcI stavkih uporablja tako rekoč samo nedoločnik glagola »biti« (»to be«) ali nedoločnik katerega drugega stanjskega glagola. Pojav je bil posebne pozornosti deležen $\mathrm{v}$ okviru slovenske teorije naravne skladnje, ki se razvija pod vodstvom Janeza Orešnika. V tej teoriji je omejitev na stanjske glagole znamenje, da so stavki AcI šibka (oz. bolj naravna) dvojnica v primerjavi s finitnimi odvisniki, ki AcI stavke lahko nadomeščajo. $\mathrm{V}$ delih s tega področja naletimo tudi na natančnejše podatke v zvezi z rabo stanjskih glagolov v omenjeni latinski konstrukciji. Kot ugotavlja Orešnik (1999: 77), v arhaični komediji infinitiv glagola »biti« (esse) znotraj te konstrukcije močno prevladuje nad drugimi infinitivi: rabljen je v $59 \%$ primerov, medtem ko se v isti konstrukcij za glagoli mišljenja pojavlja v $49 \%$ primerov. Ob tem je glagol »biti« v finitnih stavkih precej manj pogost in predstavlja okrog $19 \%$ vseh osebnih glagolskih oblik (loc. cit.). ${ }^{2}$

Kot kaže spodnja slika, lahko o podobni težnji govorimo tudi v klasičnih latinskih besedilih:

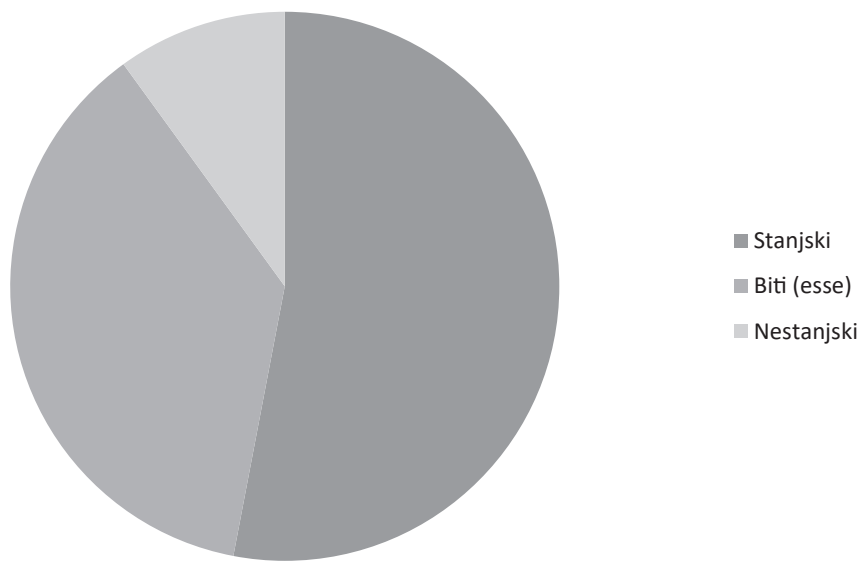

Slika 1: Konstrukcija AcI/NcI v klasični latinščini

Podatki se nanašajo na okrog $800 \mathrm{AcI} / \mathrm{NcI}$ stavkov, odvisnih od glagola putare (»misliti«) v izbranih Ciceronovih delih, in kažejo, da v tej konstrukciji močno prevladujejo stanjski infinitivi prezenta, kakršen je esse (poleg denimo posse, valere, habere, oportere in debere); primer je zgornji stavek št. (1). ${ }^{3}$ Samo okrog $10 \%$ infinitivov prezenta je

2 Za starejši pogled na problematiko gl. Kavčič (2010: 209-214).

3 Analizirana dela: In Verrem, In Catilinam, Pro Archia poeta, Brutus, Orator, De optimo genere oratorum, Epistulae ad familiares, Epistulae ad Atticum. 
nestanjskih (npr. facere, dicere, scribere itd.). Tudi v primeru izražanja zadobnosti in preddobnosti prevladujeta infinitiva glagola »biti«, to sta infinitiv futura fore in infinitiv perfekta fuisse. Kot že rečeno, je ta pogostnost nedoločnikov glagola biti bistveno višja od pogostnosti osebnih oblik tega glagola v finitnih stavkih.

Morda je naključje, da tudi najstarejši primer obravnavane konstrukcije v stari grščini - in v klasičnih jezikih na splošno - vsebuje stanjski glagol. To je infinitiv prezenta glagola imeti oz. e-ke-e, ki usteza klasičnemu infinitivu prezenta é $\chi \varepsilon ı v$, stavek pa je izpričan na eni izmed tablic iz mikenskega obdobja (ok. 1200 pr. Kr.; prim. Duhoux 2000: 256):

(6) i-je-re-ja e-ke-ke e-u-ke-to-qe e-to-ni-jo e-ke-e (Py. Eb 297) Svečenica ima in trdi, da ima v lasti posest. ${ }^{4}$

Bistveno manj verjetno pa je, da je posledica naključja težnja po stanjskosti, ki jo izražajo AcI/NcI stavki v kasnejših starogrških besedilih. Statistični podatki kažejo, da je - vsaj v primerih, ko je v AcI/NcI stavku rabljen infinitiv prezenta - daleč najpogostejši infinitiv prezenta glagola biti (Eĩval); njegova relativna pogostnost dosega denimo $43 \%$ vseh AcI/NcI stavkov pri Platonu, 35 \% pri Homerju, 33 \% pri Ksenofontu, 30 \% pri Aristofanu, 47 \% v Novi Zavezi (Kavčič 2010: 2011, 2017: 92). ${ }^{5}$ Tudi v tem primeru velja, da pogostnost nedoločnika glagola »biti« v AcI/NcI stavkih ne more odslikavati razmer v stari grščini na splošno, ker je glagol »biti« v finitnih stavkih bistveno manj pogosten (Kavčič 2010: 211).

Med latinščino in grščino obstaja tudi manjši razloček. Za grščino je mogoče trditi, da težnja k rabi stanjskih glagolov obstaja, kolikor upoštevamo AcI/NcI stavke, ki vsebujejo infinitiv prezenta in torej izražajo istodobnost. Nekoliko manj opore pa ima trditev, da v teh stavkih na splošno, torej tudi v tistih, ki izražajo zadobnost ali preddobnost, prevladuje glagol »biti« (ali drugi stanjski glagoli). To je brez dvoma povezano z dejstvom, da v grščini nedoločniki, ki se uporabljajo za izražanje omenjenih časovnih razmerij, niso opisni in se torej - za razliko od latinščine, kjer se infinitiv futura ter infinitiv perfekta pasiva tvorita opisno z nedoločnikom esse - ne tvorijo z nedoločnikom glagola biti. Zastaviti si je mogoče tudi vprašanje, kaj bi v grščini sploh ustrezalo latinskemu infinitivu fuisse (oz. »preddobni« različici infinitiva prezenta glagola biti, lat. esse / gr. Eĩval); o tem bo več govora v naslednjem razdelku. V grščini je torej težnjo po stanjskosti videti zlasti v primerih, ko se v AcI/NcI stavku uporablja infinitiv prezenta in se posledično izraža istodobnost. Ta zaključek je pomemben tudi z vidika pojava, ki bo obravnavan v nadaljevanju.

4 Ostale besede $\mathrm{v}$ istem stavku bi ustrezale naslednjim klasičnim (atiškim) oblikam, zapisanim z grškim alfabetom:

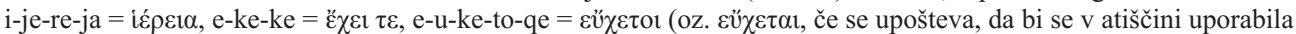

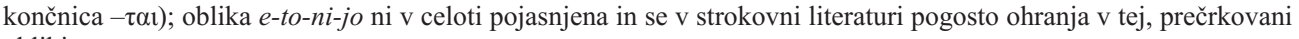
obliki.

5 Podatki se nanašajo na več sto primerov AcI/NcI stavkov klasičnih piscev; prim. loc. cit. 


\subsection{Preddobnost $v$ grščini}

\subsubsection{Infinitiv perfekta in preddobnost}

Kot je bilo povedano že v uvodnem poglavju, Bentein (2018: 88-89) v nasprotju s tradicionalnimi slovnicami, ki vprašanje rabe infinitiva perfekta $\mathrm{v}$ AcI/NcI stavkih ne obravnavajo podrobneje, trdi, da se je v klasični grščini infinitiv perfekta uporabljal v vlogi izražanja preddobnosti.

O pomembni vlogi infinitiva perfekta $\mathrm{v}$ AcI/NcI stavkih priča vrsta opažanj o poklasični grščini - ki vsaj deloma govorijo tudi v prid prej omenjenemu Benteinovemu stališču. Mandilaras (1973: 329) tako ugotavlja, da je v poklasičnih neliterarnih besedilih (ohranjenih na papirusu), infinitiv perfekta daleč najpogostejši infinitiv, ki se uporablja v AcI/NcI stavkih (za katere uporablja izraz ötı-nedoločnik). Podobno je stanje v Novi Zavezi, kjer je visoko pogostnost infinitiva perfekta v omenjenih stavkih opazil že Fanning (1990: 401-402).

Ista poklasična besedila po drugi strani kažejo, da je tako rekoč odsoten infinitiv aorista (ki bi se v isti konstrukciji uporabljal v vlogi izražanja preddobnosti). Odsotnost te konstrukcije v Novi Zavezi je opazil Burton (1898: 53), njegovo opažanje pa ponovijo - ne da bi zanjo ponudile razlago - nekatere novejše študije (Fanning loc. cit., Thorley 1989: 295). V poklasičnih in zgodnjebizantinskih literarnih besedilih, ki so tako kot Nova Zaveza napisana v nižjem registru in torej v slogovnem smislu niso pod pomembnejšim vplivom klasične grščine, je infinitiva aorista sicer nekoliko več, pri čemer pa je njegova relativna pogostnost razmeroma nizka in praviloma ne presega $5 \%$ vseh nedoločnikov v AcI stavkih (Kavčič 2017: 99; Kavčič 2019). Ta relativna pogostnost je nepričakovana, če se postavimo na stališče večine slovnic stare grščine, da namreč infinitiv aorista, tako kot drugi infinitivi, rabljeni znotraj konstrukcije AcI/NcI, v tej konstrukciji opravljajo vlogo, identično $\mathrm{z}$ vlogo indikativa $\mathrm{v}$ finitnih stavkih (prim. razdelek 2). Ker je indikativ aorista $\mathrm{v}$ indikativnih stavkih bistveno bolj pogosten čas - po podatkih, ki jih navaja Duhoux (2000: 155), je to celo najpogostejši starogrški čas -, bi pričakovali, da bo tudi infinitiv aorista $v$ AcI/NcI stavkih pogostejši od drugih nedoločnikov. Stanje je drugačno: že v klasični dobi je (relativna) pogostnost infinitiva aorista $\mathrm{v}$ AcI/NcI stavkih razmeroma nizka, giblje se med $5 \%$ vseh nedoločnikov (pri Ksenofontu) in $27 \%$ (pri Herodotu), v prej omenjenih poklasičnih besedilih pa dodatno upade (prim. Kavčič 2017: 94; Bentein 2018: 89). ${ }^{6}$ Ta pogostnost je obenem nižja od pogostnosti infinitiva prezenta, v klasični dobi pa tudi od infinitiva futura; v poklasični dobi sicer pogostnost slednjega nekoliko upade zaradi postopnega izginjanja starogrškega sintetičnega futura, a večinoma ostane na primerljivih ravneh s pogostnostjo infinitiva aorista (Kavčič 2016: 284).

Kot rečeno, bi visoka pogostnost infinitiva perfekta $\mathrm{v}$ AcI/NcI stavkih lahko govorila v prid domnevi, da je ta infinitiv opravljal vlogo izražanja preddobnosti. A poudariti

6 Prim. op. 5. 
velja, da za zgoraj omenjena dejstva velja tudi drugačna razlaga. Ta izhaja iz prej omenjene težnje, ki jo izpostavlja slovenska šola teorije naravnosti in je obenem v skladu s Thorleyevim opažanjem o poklasični grščini, da so namreč AcI/NcI stavki tako rekoč v celoti omejeni na izražanje (istodobnih) stanj. Odsotnost infinitiva aorista se v tem primeru pojasni z dejstvom, da infinitiv aorista stanjskih glagolov praviloma na izraža stanj, temveč ima inkohativni (ali začenjalni) pomen in torej izraža vstop v stanje. To je značilnost dovršnih glagolskih oblik v mnogih jezikih, med drugim tudi aoristovih oblik v stari grščini (prim. Fanning 1990: 96). Visoka relativna pogostnost infinitiva perfekta $\mathrm{v}$ isti konstrukcij se prav tako pojasni s težnjo po stanjskosti: povsem pričakovana je namreč, če se postavimo na v uvodu omenjeno Rijksbaronovo stališče, da infinitiv perfekta $\mathrm{v}$ AcI/NcI stavkih izraža istodobna stanja.

A omenjena razlaga naleti na vrsto težav ob obravnavi posameznih primerov, v delnem neskladju pa je tudi z domnevami o razvoju perfekta v poklasični grščini. Besedila, ki izpričujejo visoko relativno pogostnost infinitiva perfekta v AcI stavkih, obenem izpričujejo stavke, kakršen je naslednji:

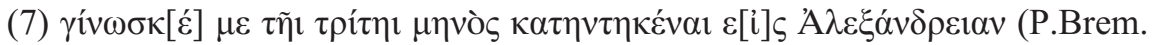
48 vv. 3-4, 118 po Kr.) Vedi, da sem tretjega v mesecu prispel v Aleksandrijo.

$\mathrm{V}$ tem primeru izraža infinitiv perfekta glagola $\kappa \alpha \tau \alpha v \tau \tilde{\omega}$ (»prispeti«) dejstvo, da je avtor pisma prispel v Aleksandrijo. Težko trdimo, da AcI stavek izraža stanje in da je to stanje istodobno s časom nadrednega glagola; njegovo časovno nanašanje je jasno izraže-

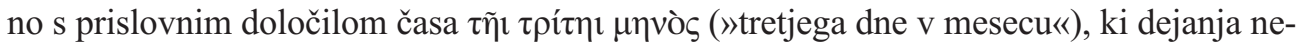
določniškega polstavka postavlja v preddobnost glede na čas, izražen v nadrednem glagolu. Stavki, kot je prej omenjeni, na neliterarnih papirusnih najdbah niso redki in jih lahko vzporejamo z prej omenjenim angleškim stavkom (št. 4), v katerem ima angleški infinitiv perfekta (»to have been«) enako vlogo, kot jo ima v finitnih stavkih angleški simple past.

To obenem potrjuje domnevo, da se (vsaj v poklasični dobi) v vlogi izražanja preddobnosti, konkretneje v vlogi dovršnega preteklika (ali indikativa aorista), v AcI/NcI stavkih uporablja infinitiv perfekta. Odsotnost infinitiva aorista iz enake vloge pa se v tem primeru ne razloži s težnjo po stanjskosti teh stavkov, temveč kot posledica širitve perfekta v poklasični grščini. Splošno sprejeto je namreč že v uvodu omenjeno dejstvo, da je bil perfekt v klasični dobi razmeroma redek, a da se je njegova pogostnost povečala v poklasični dobi, preden je ob koncu antike iz jezika izginil (prim. Bentein 2016: 156); perfekt se je obenem po svoji rabi vse bolj približeval dovršnemu pretekliku ali (grške$\mathrm{mu}$ ) aoristu - zato je razlaga, ki odsotnost infinitiva aorista in visoko pogostnost infinitiva perfekta v poklasičnih AcI/NcI stavkih povezuje s težnjo po stanjskosti teh stavkov, neskladna $\mathrm{z}$ domnevami o razvoju perfekta v poklasični dobi.

Po tej razlagi so bile razmere v AcI/NcI stavkih, vsaj kar se tiče izražanja preteklosti v poklasični grščini, drugačne kot v finitnih stavkih, podobno kot v prej omenjenih 
modernih jezikih. Vendar pa razlike med nedoločniškimi in finitnimi stavki ni mogoče pojasniti na enak način kot v modernih jezikih: kot pravi Comrie (1981: 55), se v angleščini infinitiv perfekta uporablja v vlogi izražanja preddobnosti zato, ker »ni na voljo drugega infinitiva«. Stara grščina v tej vlogi namreč pozna še najmanj en infinitiv, to je infinitiv aorista. ${ }^{7}$ Razlika med starogrškimi nedoločniškimi in finitnimi stavki pa se kljub temu pojasni, če se upošteva dobro znano dejstvo, da se v stari grščini indikativ aorista tvori z avgmentom, ki je oblikoslovno sredstvo za izražanje preteklosti, in da infinitiv aorista avgmenta nima. Posledica je, da se infinitiv aorista, kadar je odvisen od glagolov govorjenja in mišljenja, ne nanaša nujno na dejanska pretekla dejanja - to velja za $\mathrm{v}$ tem članku obravnavano konstrukcijo -, ampak tudi na (potencialna) dejanja v prihodnosti ali celo na istodobna dejanja. Kot primer lahko navedemo novozavezni stavek $\delta i \grave{~} \tau \tilde{\eta} \varsigma$

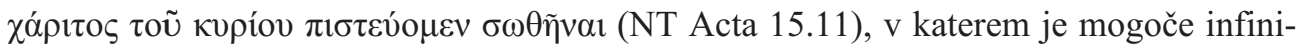
tiv aorista $\sigma \omega \theta \tilde{\eta} v a$ r razlagati kot preddobnega, zadobnega ali istodobnega glede na čas nadrednega stavka (prim. Kavčič 2016: 293; Bentein 2018: 104). Stavek se zato lahko prevede kot »Verjamemo, da smo rešeni po gospodovi milosti« - tej interpretaciji sledi standardni slovenski prevod Nove Zaveze -, v vsaj teoretičnem smislu pa tudi kot »Verjamemo, da bomo rešeni po gospodovi milosti« ali »Verjamemo, da smo bili rešeni po gospodovi milosti«. Infinitiv perfekta je bil po drugi strani v primerjavi z infinitivom aorista $\mathrm{v}$ časovnem smislu bistveno bolj transparenten - vsaj če upoštevamo, da je bila njegovo vloga že v klasični dobi podobna vlogi perfekta $\mathrm{v}$ prej omenjenih modernih jezikih - kar razloži težnjo po njegovem uveljavljanju v vlogi izražanja preddobnosti (prim. loc. cit.). Kot bo pokazal naslednji razdelek, so v skladu s to razlago tudi težnje, značilne za rabo infinitiva aorista $v$ vlogi izražanja preddobnosti.

Čeprav se zdi zgoraj omenjeni pogled na vlogo infinitiva perfekta v AcI/NcI stavkih v nasprotju s prevladujočim pogledom na izražanje časovnih razmerij v AcI/NcI stavkih, pa je mogoče v njegovo podporo navesti tudi starejša opažanja. Harry (1906: 69) tako omenja, da se v poklasični dobi, deloma pa tudi že v mlajši prozi klasične dobe, v grščini uveljavi infinitiv, soroden latinskemu fuisse; slednji je preddobna različica infinitiva prezenta glagola biti (lat. esse, gr. Eĩval). Ker te vloge ni mogel prevzeti infinitiv glagola

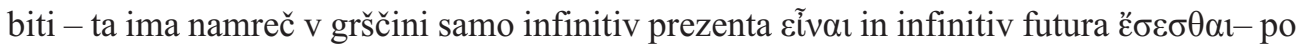

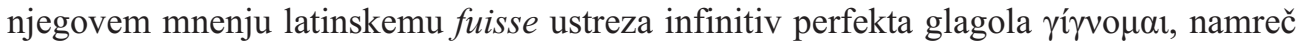

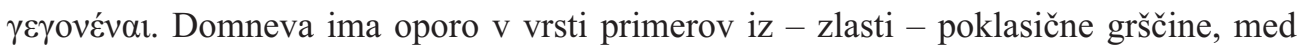
drugim v naslednjem:

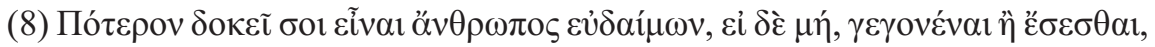
(D. Chr. 23.1) Ali se ti zdi, da je človek srečen, in če to ne drži, da je bil ali da bo srečen?

7 Občasno je v tej vlogi izpričan tudi infinitiv prezenta, pri čemer je tudi izražanje preddobnosti infinitiva prezenta omejeno na določene kontekste (prim. Kavčič v tisku). 
Najbolj prepričljiva razlaga tega stavka je, da je stanje srečnosti izraženo z infinitivom prezenta عĩval, ko se izraža istodobnost (»da je človek srečen«), z infinitivom futura

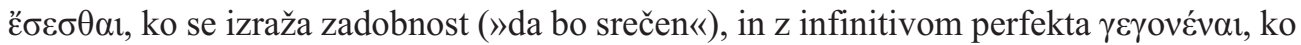
se izraža preddobnost (»da je bil srečen«). Ta raba infinitiva perfekta je skladna z razlago, da se je v stari grščini postopoma uveljavljal v vlogi izražanja preddobnosti v AcI/NcI stavkih infinitiv perfekta - in ostane nepojasnjena, če se postavimo na stališče, da je imel to vlogo infinitiv aorista. ${ }^{8}$ Obenem velja poudariti, da se infinitiv perfekta v zgornjem primeru uporablja $\mathrm{v}$ nedovršnem pomenu (stanje, ki ga izraža, ni bilo zaključeno), medtem ko je infinitiv aorista - tako kot vsaka aoristova oblika v grščini - dovršen. Zato se zdi smiselna domneva, da bi bil v zgornjem stavku infinitiv aorista (katerega koli) glagola nesprejemljiv. Primer tako priča, da je infinitiv perfekta (zlasti) v poklasični grščini soroden $\mathrm{z}$ infinitivom perfekta $\mathrm{v}$ modernih jezikih tudi $\mathrm{v}$ tem smislu, da se $\mathrm{v}$ AcI/NcI stavkih lahko uporablja tako dovršno kot nedovršno, to pa je bil morda dodaten razlog, zakaj je v poklasičnih dobi v omenjeni konstrukciji prevladal v vlogi izražanja preddobnosti.

\subsubsection{Infinitiv aorista in preddobnost}

Kot rečeno, tudi težnje $\mathrm{v}$ rabi infinitiva aorista $\mathrm{v}$ vlogi izražanja preddobnosti govorijo $\mathrm{v}$ prid domnevi, da se je $\mathrm{v}$ tej vlogi postopoma uveljavljal infinitiv perfekta. Te težnje obenem postavljajo v novo luč tradicionalni pogled na vlogo infinitiva aorista v AcI/NcI stavkih.

Vsaj za poklasično grščino velja, da se infinitiv aorista v vlogi izražanja preddobnosti povečini pojavlja v nedvoumnih kontekstih, ki implicirajo njegovo preddobnost. V literarnih besedilih je še posebej pogost tako imenovani mitološko-zgodovinski stavčni tip (Kavčič v tisku). To so stavki, v katerih je nadredni glagol v prezentu, medtem ko se odvisni AcI/NcI stavek nanaša na dejanje, povezano z dobro znanim mitološkim ali zgodovinskim junakom, tako kot $\mathrm{v}$ naslednjem primeru:

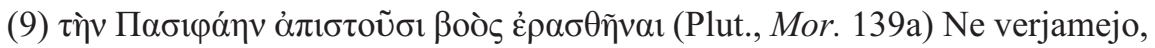
da se je Pasifaja zaljubila v bika.

Kljub odsotnosti avgmenta kot znamenja za preteklost je infinitiv aorista mogoče $\mathrm{v}$ tem primeru interpretirati zgolj kot preddobnega glede na čas, izražen v nadrednem stavku. To postane jasno, če se upošteva, naj kaj se nanaša nadredni glagol mišljenja in na kaj se nanaša tožilniški osebek nedoločniškega polstavka (ali drugače povedano, če

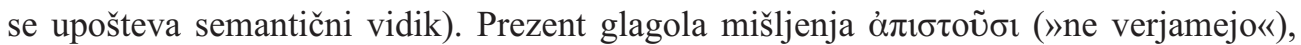
rabljenega $v$ glavnem stavku, se namreč nanaša na t.i. čas govorjenja, to je na čas, ko je avtor besedila (v tem primeru Plutarh) izrekel (ali natančneje, zapisal) omenjeni stavek.

8 Harry (loc. cit.) omenja tudi možnost latinskega vpliva na grščino, ki pa jo je primoran zavrniti, ker je pojav izpričan že v klasični grščini. 
Odvisni stavek se nadalje nanaša na dobro znani mitološki dogodek, povezan s Pasifajo: povsem jasno je, da je tako dejanje mogoče postaviti samo $\mathrm{v}$ preddobnost glede na čas, izražen v nadrednem stavku (to je na čas Plutarhovega življenja). Tako smemo trditi, da kontekst ali, natančneje, čas, izražen v glavnem stavku, ter referent (nanosnik) oseb-

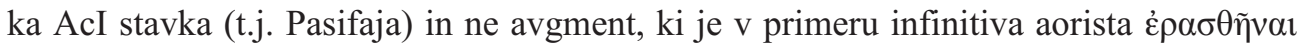
(»zaljubiti se«) odsoten, zagotavlja, da se odvisni nedoločniški polstavek interpretira kot preddoben glede na čas nadrednega stavka. Kot se zdi, ima pojav vzporednico v rabi injunktiva aorista $v$ Vedah. ${ }^{9}$

Mitološko-zgodovinski stavčni tip ima več različic; včasih se v glavnem stavku ne uporablja indikativ prezenta, temveč indikativ aorista, pri čemer se slednji nanaša na trditve antičnih, povečini historiografskih piscev, medtem ko se odvisni AcI/NcI stavek nanaša na dejanja protagonistov teh besedil (Kavčič v tisku). Poudariti velja, da navedenim različicam mitološko-zgodovinskega stavčnega tipa ustreza velika večina AcI/NcI stavkov v poklasičnih literarnih besedilih, ki izpričujejo rabo infinitiva aorista v vlogi izražanja preddobnosti, in sicer kar 82,5 \% (Kavčič v tisku).

Poklasična besedila odražajo tudi druge težnje v rabi infinitiva aorista v vlogi izražanja preddobnosti. V številnih primerih, ki ne sodijo v mitološko-zgodovinski stavčni tip, je infinitiv aorista rabljen $\mathrm{v}$ priredni zvezi s še enim infinitivom aorista (ali z infinitivom perfekta) (Kavčič 2019). Primer je naslednji stavek iz Pavzanija, v katerem se priredje dveh infinitivov aorista (namreč $\dot{\alpha} \mu \alpha \rho \tau \varepsilon \tau v \vee$ zgrešiti« in $\dot{\varepsilon} \xi \varepsilon v \varepsilon \chi \theta \tilde{\eta} v \alpha \iota$ »biti zanešen«) nanaša na dva zaporedna preddobna dogodka:

(10) ”Е

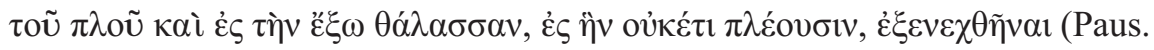
1.23.5) Karijec Evfem je rekel, da je na plovbi proti Italiji zaradi vetra zgrešil pot in da ga je zaneslo na odprto morje, do katerega se več ne pluje.

Tudi to težnjo je mogoče razložiti kot posledico odsotnosti avgmenta v primeru infinitiva aorista oz. njegove dovršnosti. Kadar stavek vsebuje več kot eno dovršno obliko, je, tako Comrie (1985: 28), najbolj »naravna« interpretacija ta, da so si dogodki, izraženi s temi dovršnimi oblikami, sledili drug za drugim; ni namreč mogoče, da bi se vsi odvili hkrati, glede na to, da so izraženi z dovršnimi oblikami in da gre posledično za zaključena dejanja. Zato ne moremo trditi, kot sklepa Comrie (loc. cit.), da je izražanje zaporednosti, v širšem smislu pa tudi časovnosti, del osnovnega pomena dovršnih oblik. Posledično lahko težnjo po tem, da se infinitiv aorista, kadar izraža preddobna dejanja, uporablja $\mathrm{v}$ prirednih konstrukcijah, ki se nanašajo na zaporedna pretekla dejanja, razumemo kot način, da glagolska oblika brez avgmenta dobi pomen preteklosti (oz. preddobnosti, kadar govorimo o njeni rabi v AcI/NcI stavkih).

9 Več o tem: Kavčič (v tisku). 
Ta tip stavka je še posebej pogost $\mathrm{v}$ zasebnih pismih helenistične dobe, medtem ko se v literarnih besedilih priredje med najmanj dvema infinitivoma aorista pojavlja $\mathrm{v}$ 5 \% AcI/NcI stavkov (Kavčič 2019; v tisku). Če upoštevamo, da je v literarnih besedilih dobrih $82 \%$ primerov infinitiva aorista v vlogi izražanja preddobnosti rabljenih v t.i. mitološko-zgodovinskem stavčnem tipu, se na ta način dodatno poveča odstotek primerov iste konstrukcije, rabljenih v kontekstih, ki implicirajo njeno preddobnost.

Naslednja, nekoliko slabše izražena težnja v rabi infinitiva aorista v vlogi izražanja preddobnosti se tiče njegove rabe v (faktivnih) AcI/NcI stavkih, odvisnih od glagolov zaznavanja. Tudi v tem primeru kontekst implicira preddobnost AcI/NcI stavka, ker je infinitiv aorista za glagoli posrednega in neposrednega zaznavanja za razliko od infinitiva aorista, odvisnega od glagolov govorjenja in mišljenja, lahko samo preddoben; gl. Kavčič (2019). V drugih primerih je preddobnost inifinitiva aorista nakazana $\mathrm{z}$ rabo ustreznega prislovnega določila časa, kar pa je - v tipološkem smislu - najobičajnešji način za izražanje časovnosti glagolskih oblik, ki izražajo vid in ne časa (prim. Smith 2008). Redkeje se preddobnost infinitiva aorista razbere iz širšega konteksta; niti ta možnost pa s tipološkega vidika ni nepričakovana (loc. cit.).

Za potrebe pričujočega članka naj dodamo, da razmere znotraj klasične grščine, kar se tiče rabe infinitiva aorista v vlogi izražanja preddobnosti v AcI/NcI stavkih, niso mogle biti v celoti drugačne kot $\mathrm{v}$ poklasičnih besedilih. O tem med drugim pričata dve Platonovi deli, Apologija in dialog Evtifron. V slednjem naletimo na zgolj dva preddobna infinitiva aorista (namreč na $\delta \tilde{\eta} \sigma \alpha l$ in $\dot{\varepsilon} \kappa \tau \varepsilon \mu \varepsilon \tau \tilde{v}$ v Evt. 5e-6a). Oba se nahajata znotraj istega stavka in se nanašata na dejanja Zevsa in njegovega očeta; ker je v glavnem stavku rabljen sedanjik, ki se nanaša na čas trajanja dialoga, in ker se s tega vidika v stavku omenjeni mitološki dogodki lahko interpretirajo samo kot preddobni, gre za t.i. mitološko-zgodovinski stavčni tip.

Apologija vsebuje štiri primere infinitiva aorista v vlogi izražanja preddobnosti; eden izmed njih je primer mitološko-zgodovinskega stavčnega tipa (Apol. 28d), kar pomeni, da v obeh delih skupaj dva od šestih primerov ustrezata temu stavčnemu tipu. V nadaljnjih dveh primerih iz Apologije je preddobnost infinitiva aorista označena s časovnim prislovom (namreč Apol. 30a in Apol. 33b) in v samo enem primeru lahko trdimo, da se časovno nanašanje tega infinitiva razbere iz širšega konteksta (gl. Apol. 26e). Omenjenih šest primerov infinitiva aorista, rabljenih v vlogi izražanja preddobnosti, nadalje predstavlja zgolj okrog $5 \%$ vseh AcI/NcI stavkov v omenjenih Platonovih delih; relativna pogostnost te konstrukcije je tako - v skladu s pričakovanji - nizka in bistveno nižja, kot bi pričakovali izhajajoč iz predpostavke, da ima infinitiv aorista $\mathrm{v} \mathrm{AcI} / \mathrm{NcI}$ stavkih enako vlogo kot indikativ aorista $\mathrm{v}$ finitnih stavkih. Obenem je skladna z domnevo, da se je infinitiv aorista $\mathrm{v}$ vlogi izražanja preddobnosti uporabljal v omejenih kontekstih.

Razmere v stari grščini se tako izkažejo za bolj zapletene kot v modernih jezikih, ker je infinitiv perfekta zgolj eden od nedoločnikov, ki se lahko uporabljajo v tej vlogi. Ker je infinitiv aorista izražal glagolski vid in ne relativnega časa (preddobnosti), je bila njegova 
raba, kot kaže, omejena na predvidljive kontekste - kar je vidik, ki ga tradicionalne slovnice ne poznajo. ${ }^{10}$ Prav dejstvo, da se je infinitiv aorista v vlogi izražanja preddobnosti lahko uporabljal zgolj v omejenih kontekstih in - za razliko od infinitiva perfekta - v izključno dovršni rabi, pa je lahko pripomogla k postopnem uveljavljanju infinitiva perfekta $\mathrm{v}$ enaki vlogi. Zato težnje, značilne za rabo infinitiva aorista v AcI/NcI stavkih, dajejo dodatno oporo domnevi o uveljavitvi infinitiva perfekta $\mathrm{v}$ vlogi izražanja preddobnosti $\mathrm{v}$ teh stavkih. Ne gre izključiti niti možnosti, da je imel ta infinitiv enako vlogo že v klasični dobi in da je že tedaj lahko prevzel $\mathrm{v}$ tej konstrukciji vlogo indikativa aorista $\mathrm{v}$ finitnih stavkih (prim. 2). A v podkrepitev te teze bi bilo potrebno navesti prepričljive primere, v katerih bi se infinitiv perfekta povezoval z za to vlogo značilnimi prislovnimi določili časa, kakršni so izpričani v poklasični grščini (gl. primer 7). V nasprotnem primeru je bolj verjetno, da je bila vloga infinitiva perfekta v AcI/NcI stavkih v klasični grščini omejena na vlogo, kakršno ima $v$ finitnih stavkih indikativ perfekta.

\subsection{Izražanje istodobnosti in preddobnosti v Acl/Ncl stavkih: zaključki}

Če povzamemo, zasledimo pri izražanju časovnih razmerij v latinskih in grških AcI/NcI stavkih naslednje težnje. Prvič, oba jezika (tako kot nekateri moderni jeziki) v omenjenih stavkih izražata težnjo po stanjskosti. Ta težnja bi lahko razložila tudi proces, ki je, kot kaže, zajel grščino v poklasični dobi; namreč uveljavljanje infinitiva perfekta v AcI/ NcI stavkih in izginjanje infinitiva aorista iz te konstrukcije. A spričo jasnih nestanjskih primerov konstrukcije AcI/NcI, izpričanih v poklasičnih besedilih, pa tudi zaradi težnje, da bi se perfekt $\mathrm{v}$ poklasični dobi uveljavil kot pretežno pretekli čas, je bolj prepričljiva razlaga, ki odsotnost infinitiva aorista povezuje s širitvijo infinitiva perfekta, ta pa je v konstrukciji prevzel vlogo izražanja preddobnosti.

Dodati velja, da omenjena razlaga temelji na predpostavki, da je infinitiv aorista izražal (dovršni) glagolski vid in ne relativnega časa. Čeprav je ta predpostavka dandanes široko sprejeta, je naleteti tudi na drugačno stališče, in sicer, da je aoristova osnova, s tem pa tudi infinitiv aorista v stari gř̌čini, izražal relativni čas (natančneje, preddobnost). Kot argument $\mathrm{v}$ podporo temu stališču se navajajo prav stavki, o katerih je govor $\mathrm{v}$ pričujočem članku, namreč AcI/NcI stavki, v katerih ta infinitiv izraža (dejansko) preddobno dejanje. To stališče zavzameta (denimo) Miller (2002: 34) in Bary (2012: 43), ki nekoliko protislovno zatrjuje, da je treba starogrške povedne nedoločnike interpretirati, kot da bi imeli časovne morfeme, čeprav to ne velja za nobenega od infinitivov razen za infinitiv futura. A v tem primeru je težko razložiti, zakaj bi se infinitiv aorista uporabljal v prej omenjenih napovedljivih kontekstih, ki implicirajo njegovo preddobnost. Te težnje se lahko pojasnijo, če se predpostavi, da infinitiv aorista izraža (dovršni) vid in ne (relativnega) časa.

10 Nekaj podobnega velja za (̌̌e redkejši) infinitiv prezenta v vlogi izražanja preddobnosti; prim. op. 7. 
Čeprav se zdi razlaga, ki povezuje umikanje infinitiva aorista iz vloge izražanja preddobnosti v AcI/NcI stavkih s širitvijo infinitiva perfekta, v vsaj delnem nasprotju $\mathrm{z}$ idejo o stanjskosti in s tem tudi s teorijo naravnosti, pa tudi razmere $\mathrm{v}$ grščini slednji pritrjujejo v tem smislu, da je večina $\mathrm{AcI} / \mathrm{NcI}$ stavkov, tudi če upoštevamo nestanjske primere $\mathrm{z}$ infinitivom perfekta $\mathrm{v}$ vlogi izražanja preddobnosti, stanjskih (prim. 3.2.1). V Novi Zavezi je denimo daleč najpogostejši nedoločnik v AcI stavkih infinitiv prezenta glagola biti (E⿱一𫝀v $\alpha$ ), ki predstavlja $47 \%$ vseh nedoločnikov v tej konstrukciji, primerljivo težnjo pa je opaziti tudi v drugih starogrških besedilih (gl. 3.1). Ti podatki imajo - poleg tega, da so skladni s predpostavkami teorije naravnosti - tudi nekaj uporabnih vidikov, ki so obravnavani v zadnjem delu članka.

\section{UPORABNI VIDIKI IZRAŽANJA ČASOVNIH RAZMERIJ} V ACI/NCI STAVKIH

\subsection{Obravnava stanjskosti/istodobnosti v didaktičnem procesu}

Zlasti kadar je govor o izražanju istodobnosti, se tako v latinščini kot grščini izraža težnja po rabi infinitiva prezenta stanjskih glagolov (prim. 3.1). Analiza učbenikov in priročnikov, ki se uporabljajo pri pouku klasičnih jezikov na Slovenskem, pričakovano pokaže odstopanja od te težnje. Prvi primer je temeljna slovenska šolska slovnica latinskega jezika (Kopriva 1989: 210-211). V tem prikazu naletimo ne le na primere s stanjskim infinitivom prezenta, temveč tudi na primer z nestanjskim glagolom lego »berem « (npr. Dico puerum legere). Podobni primeri - ki sicer niso v celoti nesprejemljivi, temveč v izvirnih besedilih redki - se najdejo tudi v drugih priročnikih. ${ }^{11}$ Morda po naključju pa nestanjskih primerov za rabo infinitiva prezenta $\mathrm{v}$ AcI/NcI stavkih sploh ne najdemo $\mathrm{v}$ lekciji, ki je tej konstrukciji (v stari grščini) posvečena v učbeniku Kantharos (Elliger et al. 1998). Vaje, v katerih se da-stavki pretvarjajo v konstrukcijo AcI (in obratno), deni-

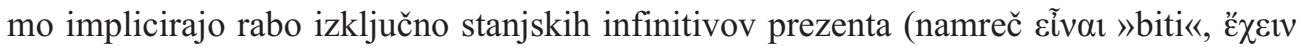

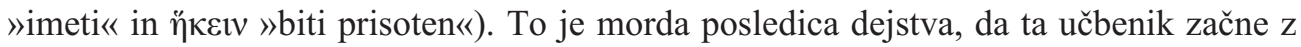
obravnavo konstrukcije AcI razmeroma zgodaj, to je $\mathrm{v} 3$. lekciji, ko učenci razpolagajo $\mathrm{z}$ razmeroma pičlim besednim zakladom in ni pričakovati, da bi v konstrukciji lahko uporabili redkejše (in obenem nestanjske) glagole.

Naj gre za naključje ali ne, prav primer učbenika Kantharos navaja k morda najbolj pomembnemu sklepu, ki izhaja iz težnje po rabi stanjskih glagolov znotraj AcI/NcI stavkov. Ker so v tej konstrukciji daleč najpogostejši ravno najpogostejši stanjski glagoli, ki se posledično praviloma pri pouku obravnavajo razmeroma zgodaj, ni razloga, da se ne

11 Prim. Čepon (2008: 47), kjer je treba odvisni govor pretvoriti v AcI stavek z nestanjskih glagolom premikanja (namreč appropinquare), ali Mihevc-Gabrovec (2011: 20), kjer je treba v grščini prevesti AcI stavek z nestanjskim glagolom. 
bi tudi obravnava te konstrukcije začela na razmeroma zgodnji stopnji, tako kot v omenjenem učbeniku.

Ob obravnavi drugih časov se tej (»osnovni«) konstrukciji AcI/NcI s po večini stanjskimi infinitivi prezenta lahko dodajajo primeri z nedoločniki, ki izražajo druga časovna razmerja. Pri tem posebej v primeru stare grščine velja, da so nekoliko pomembnejši od primerov AcI/NcI stavkov z infinitivom aorista tisti, ki vsebujejo infinitiv futura. Kot rečeno, je bil slednji v klasični grščini pogostejši v AcI/NcI stavkih kot infinitiv aorista, medtem ko je v poklasičnih besedilih kljub postopnemu umikanju starogrškega sintetičnega futura njegova relativna pogostnost primerljiva $\mathrm{z}$ infinitivom aorista (prim. razdelek 3.2.1).

Medtem ko priročniki obravnavajo tako infinitiv aorista kot infinitiv futura znotraj AcI/NcI stavkov (oba v približno enaki meri), pa je drugače z infinitivom perfekta.

\subsection{Obravnava infinitiva perfekta v grških $\mathrm{Acl} / \mathrm{Ncl}$ stavkih}

Kljub temu, da vprašanje, ali je infinitiv perfekta imel že v klasični dobi prevladujočo vlogo izražanja preddobnosti v AcI/NcI stavkih, ostaja odprto, so statistični podatki jasni. Že v klasični dobi je bil infinitiv perfekta v tej vlogi približno enako pogosten kot infinitiv aorista, njegova pogostnost pa naraste $\mathrm{v}$ poklasični dobi, ko je infinitiv aorista $\mathrm{v}$ tej vlogi zelo redek. Infinitiv perfekta (in ne infinitiv aorista), namreč $\gamma \varepsilon \gamma o v \varepsilon ́ v \alpha l, j e$, kot kaže, prevzel tudi vlogo, ki jo ima v latinščini infinitiv perfekta fuisse.

Spričo povedanega bi morala obravnava AcI/NcI stavkov namenjati rabi infinitiva perfekta vsaj enako pozornost kot rabi infinitiva aorista. Temu v obravnavanih učbenikih stare grščine ni tako: infinitivu aorista je namenjeno več pozornosti kot infinitivu perfekta, gotovo zaradi tradicionalnega prepričanja, da je infinitiv aorista sredstvo za izražanje preddobnosti v tej konstrukciji. V najpomembnejšem slovenskem učbeniku za staro grščino (Mihevc-Gabrovec 2011) se primeri AcI/NcI stavkov, ki vsebujejo infinitiv perfekta, najdejo v grških stavkih, kar je pričakovano, če se upošteva, da učbenik temelji na izvirnih starogrških primerih. V različnih lekcijah se najdejo štirje tovrstni primeri, ki so obenem številnejši od infinitiva aorista v vlogi izražanja preddobnosti - slednji se najde v zgolj enem stavku (gl. Mihevc-Gabrovec 2011: 89-90; 93). Drugače pa je v slovničnih vajah, ki ne temeljijo neposredno na izvirnih starogrških primerih in tovrstnih primerov sploh ne vsebujejo. Zato zlahka nastane vtis, da je bila vloga infinitiva perfekta v starogrških AcI/NcI stavkih povsem obrobna. Značilna in povsem v skladu s tradicionalnim pogledom na izražanje časovnih razmerij v AcI/NcI stavkih je tudi obravnava te konstrukcije v (angleškem) učbeniku, ki se prav tako uporablja v slovenskem prostoru (Learn to Read Greek). Ta vsebuje vajo (Keller in Russell 2012: 383), v kateri je treba prevesti starogrške primere poročanega govora in podčrtati primere konstrukcije AcI, med katerimi se najdejo naslednji: 


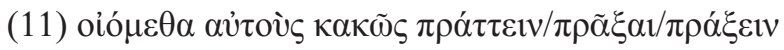

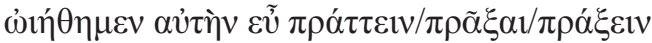

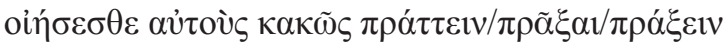

Problem te in podobnih vaj je, da ne vsebuje primerov za infinitiv perfekta in tako ne upošteva pogostnosti in vloge, ki jo je imel infinitiv perfekta v tej konstrukciji (prim. zgoraj, 3.2.1 in 3.2.2). V nasprotju s prakso na tem mestu analiziranih učbenikov obravnava starogrških AcI/NcI stavkov prav tako ne bi smela obiti primerov z infinitivom perfekta

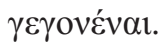

\subsection{Obravnava infinitiva aorista v vlogi izražanja preddobnosti}

Težnje, značilne za rabo infinitiva aorista v vlogi izražanja preddobnosti, nadalje omogočajo, da se obravnava te konstrukcije v pedagoškem procesu osredotoča na nekatere tipe stavkov.

Kot rečeno, je v literarnih besedilih - ta pa so v središču pouka klasičnih jezikov še posebej pogost tako imenovani mitološko-zgodovinski tip stavka (prim. 3.2.2). V tem članku obravnavani učbeniki (za staro grščino) občasno navajajo tudi tovrstne primere; denimo učbenik Keller in Russell (2012: 385), kjer se infinitiv aorista glagola viкá $\omega$

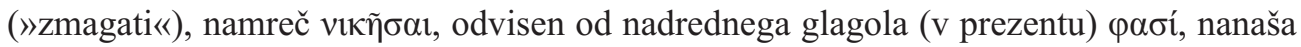
na Sokrata in njegovo vzgojo mladine:

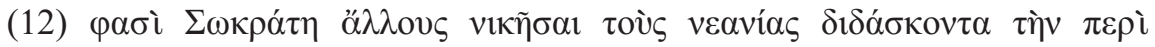

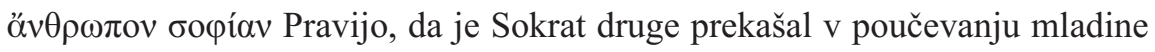
o človeški modrosti. ${ }^{2}$

Na enak tip stavka naletimo tudi v grških primerih učbenika Erike Mihevc-Gabrovec (2011: 113):

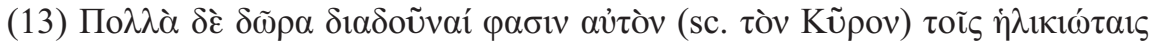
Pravijo, da je vrstnikom razdelil mnogo darov.

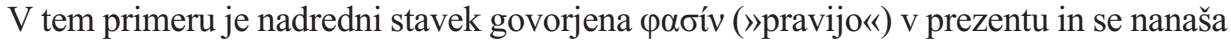
na čas govorjenja, to je na čas, ko je avtor besedila Ksenofont (431-354 pr. Kr.) stavek formuliral, medtem ko se odvisni AcI stavek nanaša na znamenitega perzijskega vladarja Kira (okr. 600-530 pr. Kr.). Ker se stavek nahaja v delu Kirova vzgoja (prim. Cyr. 1.4.26),

12 Vprašanje je sicer, na kateri čas se v tem primeru nanaša prezent v nadrednem stavku ( $\varphi \alpha \sigma i ́$ »pravijo«). Ker ni videti, da bi šlo za stavek iz izvirnega grškega besedila, se zdi, da se prezent v tem primeru nanaša na sedanjost $\mathrm{z}$ vidika avtorjev učbenika. 
posvečenem življenju že preminulega perzijskega vladarja, gre za dejanje, ki se lahko interpretira samo kot preddobno glede na čas, izražen v nadrednem stavku.

Še ena od značilnosti infinitiva aorista v vlogi izražanja preddobnosti je težnja po povezovanju v priredne zveze, ki se nanašajo na zaporedna preddobna dejanja (prim. 3.2.2). Ta težnja se odraža v enem od primeru učbenika Kantharos (Elliger et al. 1998:

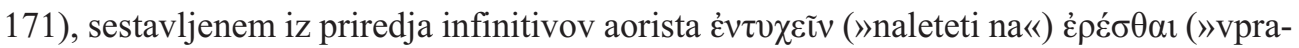
šati«) in $\varepsilon i \pi \varepsilon \tau i v(» r e c ̌ i \ll)$ :

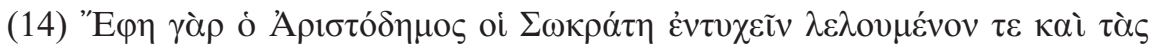

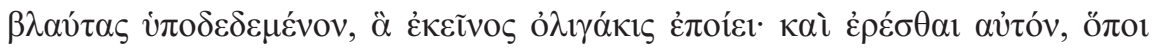

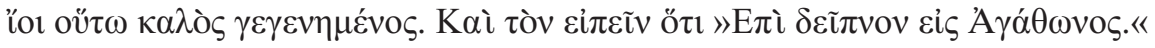
Aristodem je rekel, da je naletel na Sokrata, ki je bil umit in obut v šolne, kar je počel le redko; in vprašal ga je, kam gre tako lepo urejen, on pa je rekel: »Na večerjo k Agatonu.«

Kot pričakovano, je to citat iz izvirnega grškega besedila (Plat., Symp. 174a3-6), prav tako kot prej omenjeni stavek iz učbenika Erike Mihevc-Gabrovec. Po drugi strani pa primer stavka z infinitivom aorista, ki izraža preddobnost in se v istem učbeniku najde med slovničnimi vajami, ne sodi niti v ta niti v katerega izmed drugih prej omenjenih stavčnih tipov, značilnih za izvirna besedila; v grščino je namreč treba prevesti stavek »Pravi, da se je naučil sam« (Mihevc-Gabrovec 2011: 60). Ta kontrast ni presenetljiv; kot že rečeno, starogrški stavki v tem učbeniku za razliko od primerov v razdelku slovničnih vaj izhajajo iz izvirnih besedil.

Prav tako v neskladju s težnjami, značilnimi za izvirna starogrška besedila, je že prej omenjena vaja iz učbenika Keller in Russel (2012: 383-385), v kateri je treba podčrtati in prevesti AcI stavke (gl. zgoraj, 4.2). Vaja temelji na predpostavki, da je mogoče kateri koli stavek AcI pretvoriti v soroden AcI stavek z drugačnim časovnim razmerjem med nadrednim in odvisnim stavkom - pri čemer pa zanemarja, kot že rečeno, obstoj infinitiva perfekta. Kar se tiče rabe aorista v vlogi izražanja preddobnosti, sta v omenjeni vaji z vi-

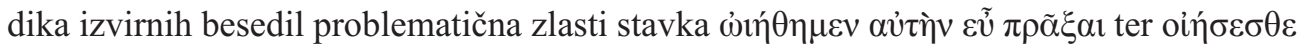

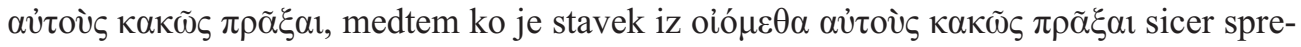
jemljivejši, a bi ga v izvirnih starogrških besedilih pričakovali predvsem v določenih kontekstih, ki so bili opisani v razdelku 3.2.2.

Čeprav se tovrstne vaje zdijo smiselne z vidika utrjevanja slovničnih pravil, pa se prepričanje, da je mogoče katero koli konstrukcijo AcI pretvoriti v sorodno infinitivno konstrukcijo, ki izraža drugačno časovno razmerje med glavnim stavkom in nedoločniškim polstavkom, izkaže za zmotno: kot je pokazala razprava v prvem delu prispevka, pri izražanju istodobnosti močno prevladujejo stanjski glagoli, medtem ko je raba infinitiva aorista v vlogi izražanja preddobnosti omejena na kontekste, ki implicirajo njegovo preddobnost. Zato se velja stavkom, kot so navedeni, v učnem procesu izogibati. 


\section{5 ZAKLJUČKI}

Novejše obravnave AcI stavkov v latinščini in grščini kažejo, da omenjena konstrukcija odraža (zlasti pri izražanju istodobnosti) težnjo k rabi stanjskih glagolov. Ta težnja bi lahko razložila tudi dejstvo, da se v vlogi izražanja preddobnosti v starogrških AcI/NcI stavkih infinitiv aorista uporablja razmeroma redko in da se je $\mathrm{v}$ isti konstrukciji postopoma vse bolj uveljavljal infinitiv perfekta. A v luči očitnih nestanjskih primerov za rabo infinitiva perfekta je bolj verjetna razlaga, da je slednji postopoma prevzemal vlogo izražanja preddobnosti v AcI/NcI stavkih. Skladna s tem je težnja infinitiva aorista, da bi se v primerih, ko izraža preddobnost dejanja, izraženega v AcI/NcI stavku, uporabljal v predvidljivih kontekstih, ki obenem implicirajo omenjeno časovno razmerje med glavnim stavkom in odvisno konstrukcijo.

Omenjeni pojavi so pomembni tudi z vidika didaktike klasičnih jezikov. Narekujejo, naj se v primeru izražanja istodobnosti (v latinščini in grščini) ter rabe infinitiva aorista v vlogi izražanja preddobnosti v grščini obravnava omeji na določene stavčne tipe, pri čemer se že na začetnih stopnjah učenja lahko obravnavajo AcI/NcI stavki z najpogostejšimi stanjskimi infinitivi prezenta (na primer »biti«, »imeti«, »moči«). V primeru starogrških $\mathrm{AcI} / \mathrm{NcI}$ stavkov pa bi bilo treba $\mathrm{v}$ nasprotju $\mathrm{z}$ dosedanjo prakso pozornost posvečati tudi rabi infinitiva perfekta $\mathrm{v}$ teh konstrukcijah.

\section{BIBLIOGRAFIJA}

BARY, Corien (2012) Tense in Ancient Greek Reports. Journal of Greek Linguistics 12, št. 1, 29-50.

BENTEIN, Klaas (2016) Verbal Periphrasis in Ancient Greek, Have- and Be-Constructions. Oxford: Oxford University Press.

BENTEIN, Klaas (2018) The Decline of Infinitival Complementation in Ancient Greek.

A Case of Diachronic Ambiguity Resolution? Glotta 94, 82-108.

BURTON, Ernest de Witt (1898) Syntax of Moods and Tenses in New Testament Greek. Edinburgh: The University of Chicago Press.

COMRIE, Bernard (1981) Aspect. Cambridge: Cambridge University Press.

COMRIE, Bernard (1985) Tense. Cambridge: Cambridge University Press.

DUHOUX, Yves (2000) Le verbe grec ancien: Éléments de morphologie et de syntaxe historiques. Louvain-la-Neuve: Peeters.

ELLIGER, Winfried/Gerhard FINK/Günther HEIL/Thomas MEYER (1998) Kantharos. Prevod: Aleš Učakar. Ljubljana: interna izdaja.

ČEPON, Robert (2008) Usus II. Ljubljana: Modrijan.

FANNING, Buist M. (1990) Verbal Aspect in New Testament Greek. Oxford: Clarendon Press. 
HARRY, Joseph E. (1906) The Perfect Forms in Later Greek from Aristotle to Justinian.

Transactions and Proceedings of the American Philological Association 37, 53-72. HASPELMATH, Martin (1992) From Resultative to Perfect in Ancient Greek. Función 11-12, 187-224.

KAVČIČ, Jerneja (2010) O prispevku slovenskega jezikoslovja k zgodovini starogrškega perfekta. Keria, Studia Latina et Graeca 12, št. 2-3, 201-216.

KAVČIČ, Jerneja (2016) The decline of the aorist infinitive in Ancient Greek declarative infinitive clauses. Journal of Greek Linguistics 16, št. 2, 266-311.

KAVČIČ, Jerneja (2017) A diachronic perspective on the semantics of AcI clause in Greek. Ł. Jędrzejowski in U. Demske (ur.), Infinitives at the syntax-semantics interface: a diachronic perspective. Berlin: De Gruyter Mouton, 81-111.

KAVČI $\breve{C}$, Jerneja (2019) Examining a hypothesis about the past-oriented aorist infinitive in Post-Classical Greek. Transactions of the Philological Society. 2. november 2019. https://onlinelibrary.wiley.com/doi/abs/10.1111/1467-968X.12164.

KAVČIČ, Jerneja (v tisku) The past-oriented aorist infinitive in Post-Classical literary texts: A parallel with the use of the aorist injunctive in Vedic Sanskrit? Glotta, Zeischrift für griechische und lateinische Sprache 96, 82-118.

KELLER, Andrew/Stephanie RUSSEL (2012) Learn to read Greek. Workbook, Part 1. New Hawen/Haven in London: Yale University Press.

KOPRIVA, Silvo (1989) Latinska slovnica. Maribor: Obzorja.

MANDILARAS, Basileios G. (1973) The Verb in Greek Non-Literary Papyri. Athens: Ministry of Education.

MIHEVC-GABROVEC, Erika (2011) Grščina. Teksti in vaje za pouk klasične grščine. 5. izd. Ljubljana: Znanstvena založba Filozofske fakultete.

MILLER, Gary D. (2002) Nonfinite Structures in Theory and Change. Oxford: Oxford University Press.

OREŠNIK, Janez (1999) Krepke in šibke dvojnice v skladnji. Ljubljana: SAZU.

POSTAL, Paul M. (1974) On Raising. Cambridge, MA: The MIT Press.

RIJKSBARON, Albert (2006) The Syntax and Semantics of the Verb in Classical Greek.

3. izd. Chicago: University of Chicago Press.

SMITH, Carlotta S. (2008) Time with and without Tense. J. Géron in J. Lecarme (ur.), Time and Modality. Dordrecht: Springer, 227-249.

TER BEEK, Janneke (2011) Two Futures in Infinitives. J.-W. Zwart in M. de Wries (ur.), Structures Preserved: Studies in Syntax for Jan Koster. Amsterdam: John Benjamins, 41-48.

THORLEY, John (1989) Aktionsart in New Testament Greek: Infinitive and Imperative. Novum Testamentum 31, 290-315.

ZWART, Jan-Wouter (2014) The Tense of Infinitives in Dutch. J. Hoeksema in D. Gilbers (ur.), A Festschrift in Honor of Frans Zwarts. Groningen: University of Groningen, 363-387. 


\section{POVZETEK}

Latinski in starogški stavki AcI in NcI izražajo težnjo po stanjskosti in so v tem smislu primerljivi z nedoločniškim polstavki v modernih jezikih (na primer v angleščini). Vzporednica med modernimi jeziki in staro grščino se nadalje kaže pri izražanju preddobnosti v obravnanih nedoločniških polstavkih: zdi se, da je v stari grščini to vlogo postopoma (od klasične dobe dalje) prevzemal infinitiv perfekta, kar je skladno $\mathrm{z}$ domnevo o istovetnosti med perfektom $\mathrm{v}$ grščini $\mathrm{v}$ omenjenem obdobju in v modernih jezikih, kakršna sta angleščina in nizozemščina (Haspelmath 1992). Razmere v grščini pa so posebne $\mathrm{v}$ tem smislu, da se $\mathrm{v}$ isti vlogi uporablja tudi infinitiv aorista (in redkeje, infinitiv prezenta) - pri čemer pa je raba omenjenih infinitivov v vlogi izražanja preddobnosti, kot se zdi, omejena na specifične, predvidljive kontekste. Eden od teh kontekstov je tako imenovani mitološko-zgodovinski stavčni tip, znotraj katerega se nadredni glagol govorjena ali mišljenja (praviloma) nanaša na čas govorjenja, medtem ko se infinitiv aorista, rabljen znotraj odvisnega nedoločniškega polstavka, nanaša na dogodek v povezavi z dobro znano mitološko ali zgodovinsko osebo (Kavčič, v tisku). Vse navedene težnje pri izražanju časovnih razmerij znotraj AcI in NcI stavkov dopolnjujejo tradicionalni pogled na te stavke v klasičnih jezikih in omogočajo izboljšavo didaktičnega procesa.

Ključne besede: klasični jeziki, AcI, NcI, preddobnost, stanjskost

\section{ABSTRACT}

\section{Expressing temporal relations in Latin And Greek AcI and NcI clauses: Some recent find- ings and their applicative aspects}

Latin and Greek AcI and NcI clauses display a tendency towards stativity, a tendency that is also observed in modern languages such as English. Furthermore, it appears that in Ancient Greek, the perfect infinitive gradually tended toward adopting the function of conveying anteriority in these constructions. This view is consistent with the assumption that Ancient Greek saw the emergence of the perfect that had much in common with the perfect in modern languages (e.g., English and Dutch) (Haspelmath 1992). Nevertheless, the situation in Ancient Greek appears to have been different in that the aorist infinitive (and rarely, the present infinitive) could convey anteriority as well - although it seems that this applies mostly in specific, predictable contexts. For instance, this was the case within the so-called mythological-historical clause type (Kavčič forthcoming). In this clause type, the governing verb of saying or thinking typically refers to the speech time, whereas the dependent infinitive clause refers to an event concerning a well-known mythological or historical hero. In addition to shedding new light on the traditional view concerning expressions of the temporal distinctions in AcI/NcI clauses (in Classical languages), these tendencies should also be taken into account in the teaching process.

Keywords: Classical languages, AcI, NcI, anteriority, stativity 